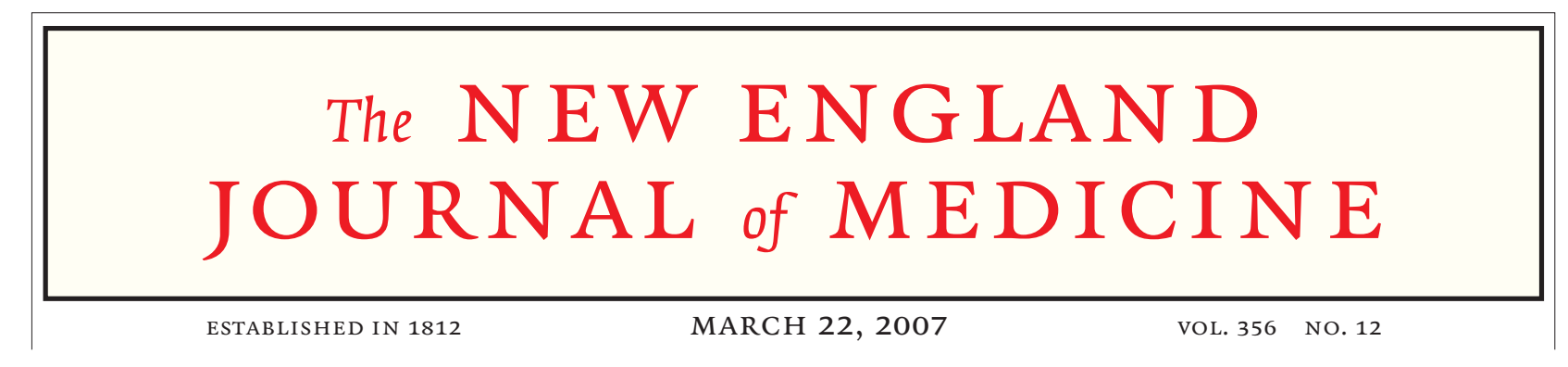

\title{
Emergency Duties and Deaths from Heart Disease among Firefighters in the United States
}

\author{
Stefanos N. Kales, M.D., M.P.H., Elpidoforos S. Soteriades, M.D., Sc.D., Costas A. Christophi, Ph.D., \\ and David C. Christiani, M.D., M.P.H.
}

ABSTRACT

BACKGROUND

Heart disease causes $45 \%$ of the deaths that occur among U.S. firefighters while they are on duty. We examined duty-specific risks of death from coronary heart disease among on-duty U.S. firefighters from 1994 to 2004.

\section{METHODS}

We reviewed summaries provided by the Federal Emergency Management Agency of the deaths of all on-duty firefighters between 1994 and 2004, except for deaths associated with the September 11, 2001, terrorist attacks. Estimates of the proportions of time spent by firefighters each year performing various duties were obtained from a municipal fire department, from 17 large metropolitan fire departments, and from a national database. Odds ratios and $95 \%$ confidence intervals for death from coronary heart disease during specific duties were calculated from the ratios of the observed odds to the expected odds, with nonemergency duties as the reference category.

RESULTS

Deaths from coronary heart disease were associated with suppressing a fire (32.1\% of all such deaths), responding to an alarm (13.4\%), returning from an alarm $(17.4 \%)$, engaging in physical training $(12.5 \%)$, responding to nonfire emergencies $(9.4 \%)$, and performing nonemergency duties (15.4\%). As compared with the odds of death from coronary heart disease during nonemergency duties, the odds were 12.1 to 136 times as high during fire suppression, 2.8 to 14.1 times as high during alarm response, 2.2 to 10.5 times as high during alarm return, and 2.9 to 6.6 times as high during physical training. These odds were based on three estimates of the time that firefighters spend on their duties.

\section{CONCLUSIONS}

Certain emergency firefighting duties were associated with a risk of death from coronary heart disease that was markedly higher than the risk associated with nonemergency duties. Fire suppression was associated with the highest risk, which was approximately 10 to 100 times as high as that for nonemergency duties.
From the Cambridge Health Alliance Harvard Medical School, Cambridge, MA (S.N.K.); the Department of Environmental Health, Harvard School of Public Health, Boston (S.N.K., E.S.S., D.C.C.); the Pulmonary and Critical Care Unit, Massachusetts General Hospital, Boston (D.C.C.); the Center for Occupational and Environmental Medicine, Kindred Hospital Northeast, Braintree, MA (D.C.C.); and the Cyprus International Institute for the Environment and Public Health in association with the Harvard School of Public Health, Nicosia, Cyprus (C.A.C.). Address reprint requests to Dr. Kales at the Cambridge Health Alliance, Employee Health and Industrial Medicine, Lee B. Macht Bldg., Rm. 427, 1493 Cambridge St., Cambridge, MA 02139, or at skales@ challiance.org.

N EnglJ Med 2007;356:1207-15. Coppright $\odot 2007$ Massachusetts Medical Society. 
F IREFIGHTING IS KNOWN TO BE A DANgerous occupation. What is less appreciated is that the most frequent cause of death among firefighters is heart disease rather than burns or smoke inhalation. Cardiovascular events, largely due to coronary heart disease, account for $45 \%$ of deaths among firefighters on duty. ${ }^{1,2}$ In contrast, such events account for $22 \%$ of deaths among police officers on duty, 11\% of deaths among on-duty emergency medical services workers, and $15 \%$ of all deaths that occur on the job. ${ }^{2,3}$ The high rate of death from cardiovascular causes among firefighters raises questions about contributing factors. Possible factors, such as physical exertion, emergency responses, and dangerous duties, are not unique to firefighting; they are also characteristic of the work performed by police officers, military personnel, and persons in various other occupations..$^{4,5}$

Various biologically plausible explanations for the high mortality from cardiovascular events among firefighters have been proposed. These explanations include smoke and chemical exposure, irregular physical exertion, the handling of heavy equipment and materials, heat stress, shift work, a high prevalence of cardiovascular risk factors, and psychological stressors. ${ }^{6-13}$ Given these occupational risks, 37 U.S. states and 2 Canadian provinces provide benefits to firefighters in whom certain cardiovascular diseases have developed. ${ }^{14}$ Nevertheless, the evidence linking firefighting to cardiovascular disease continues to be debated. ${ }^{15-17}$ Therefore, whether deaths from coronary heart disease among firefighters are truly precipitated by their work and, if so, by which duties, remain important questions.

The findings in our previous case-control study of 52 deaths from coronary heart disease among on-duty firefighters provided preliminary evidence that coronary events may be triggered by specific firefighting duties. ${ }^{18}$ First, the circadian pattern of deaths from coronary heart disease paralleled the pattern of emergency-response dispatches. Second, elevated risks of death were associated with fire suppression, alarm response, and physical training. To confirm these findings and further explore duty-specific risk factors for death from coronary heart disease, we conducted a study of all deaths that occurred among on-duty firefighters in the United States between 1994 and 2004 .

\section{METHODS}

\section{DEATHS AMONG FIREFIGHTERS}

The U.S. Fire Administration, a branch of the Federal Emergency Management Agency, collects narrative summaries for all reported deaths associated with firefighting in the United States. From these publicly available summaries, we examined data on all deaths that occurred between January 1, 1994, and December 31, 2004.2,19 The data included all firefighters who died while on duty, who became ill while on duty and later died, and who died within 24 hours after an emergency response or training. We excluded deaths that occurred during the first 48 hours after the September 11, 2001, terrorist attacks.

To extract study data, two reviewers independently examined the summary of each reported death that occurred while the firefighter was on duty. A third reviewer resolved any classifications that were not concordant between the first two reviewers. On the basis of the narrative reports, each death was classified as due to cardiovascular causes or to noncardiovascular causes. We then excluded those cases in which death occurred more than 24 hours after the on-duty incident or in which death resulted from a cardiovascular problem other than coronary heart disease (e.g., certain arrhythmias, stroke, aneurysm, or genetic cardiomyopathy).

All records of deaths that were classified by this process as being due to coronary heart disease were selected for further study. Data extracted from these records included the firefighter's age, sex, and job status (professional or volunteer); the date, cause, and mechanism of death; and the city and state of the fire department.

\section{DUties AT THE TIME OF DEATH}

On the basis of the summary report of each death, the deaths were classified according to the specific duty performed during the onset of symptoms or immediately preceding sudden death. These categories were fire suppression; alarm response; alarm return; physical training; emergency medical services, rescues, and other nonfire emergencies; and nonemergency duties. A death was classified as being associated with fire suppression if it occurred while the person was fighting a fire or at the scene of a fire after its suppression. Alarm response involved responses to 
emergency incidents, including false alarms. Alarm return included all events that occurred during the return from incidents and those that occurred within several hours after an emergency call. Physical training included all job-related physicalfitness activities, physical-abilities testing, and simulated or live fire, rescue, emergency, and search drills. We grouped together emergency medical services, rescues, and other nonfire emergencies in a separate category. Finally, we classified all of the following activities as nonemergency duties: administrative and fire-station tasks, fire prevention, inspection, maintenance, meetings, parades, and classroom activities.

\section{TIME SPENT ON SPECIFIC DUTIES}

We used data from several sources to estimate the average annual proportion of time that firefighters spend in each category. First, we directly derived point estimates from a municipal fire department (Cambridge Fire Department, Cambridge, MA), using fiscal year 2002 data, as in our previous study. ${ }^{18}$ For Cambridge firefighters, the following information was available: the number of firefighters, the total number of alarms and emergency responses, the distribution of emergency calls and dispatches by hour of the day, a breakdown of the types of incidents involved in fire and nonfire emergency responses, the average time spent per incident and the average response time, and the estimated number of hours spent each week in training and fire-prevention activities. We refer to these data as the municipal estimate.

Second, to conduct a sensitivity analysis, we obtained two additional sets of estimates, one representing a level of emergency activity that was higher than that of the Cambridge Fire Department and the other representing a lower level of emergency activity. These estimates were derived with the use of data for the population served, the numbers of uniformed officers, and the number of emergency incidents and the types of incidents classified as fire and nonfire emergencies. To characterize the largest and busiest fire departments, an estimate was developed from 2005 survey data provided by the International Association of Fire Fighters (Moore-Merrell L: personal communication) for 17 large urban and suburban fire departments (the large metropolitan estimate). To represent firefighters in smaller communities with lower levels of emergency activity, an estimate was developed from nationwide $\mathrm{Na}-$ tional Fire Protection Association surveys conducted from 1994 to 2003 (the national estimate). ${ }^{20}$

\section{STATISTICAL ANALYSIS}

We made the initial assumption that if specific firefighting duties do not have a significant effect on the risk of death from coronary heart disease, then the number of such deaths that occur during any given firefighting duty should be directly proportional to the amount of time spent performing that duty. For example, if $10 \%$ of a firefighter's time is spent in responding to alarms, $10 \%$ of deaths from coronary heart disease should occur during alarm response. We then sought to determine whether this expected pattern is or is not supported by the actual data.

Using the chi-square goodness-of-fit test, we assessed whether the distribution of actual deaths associated with each duty was the same as that of expected deaths, based on the estimates of the average time dedicated to each firefighting duty. We used the three different time estimates (from the municipal, large metropolitan, and national data) to calculate the ratios of actual to expected deaths for each firefighting duty. The $95 \%$ confidence intervals (CIs) for these ratios were calculated on the basis of the multinomial distribution. Odds ratios for death from coronary heart disease during specific duties were calculated from the ratios of the observed to expected odds, with nonemergency duties used as the reference category. The 95\% CIs for the estimated odds ratios were calculated with the use of the binomial distribution.

Using data from the 2000 firefighters census, ${ }^{21}$ which stratifies firefighters according to their age (in decades) and job status (professionals or volunteers), we calculated the rates of death from coronary heart disease for specific duties according to age and job status. Our calculations were based on death counts in each category per 1 million person-years of risk, derived from the average number of firefighters at risk in each subgroup over the 11-year period of observation.

Analyses were performed with the use of SAS software for Windows (version 8.02, SAS Institute), and StatXact (version 6.0). A P value of less than 0.05 was considered to indicate statistical significance, and all statistical tests for differences were two-sided. 


\section{RESULTS}

Between January 1, 1994, and December 31, 2004, 1144 firefighter deaths were reported to the U.S. Fire Administration. We classified 449 deaths as due to coronary heart disease (39\%). Of these deaths from coronary heart disease, 144 (32\%) occurred during fire suppression, 138 (31\%) occurred during alarm response or return, and the remaining 167 (37\%) occurred during other duties (Table 1).

\begin{tabular}{|lc|}
\hline $\begin{array}{l}\text { Table 1. Deaths from Coronary Heart Disease among Firefighters, Classified } \\
\text { According to Duty at the Time of Death.* }\end{array}$ & $\begin{array}{c}\text { Deaths } \\
(\mathbf{N}=449)\end{array}$ \\
\hline Duty & $n .(\%)$ \\
& $144(32.1)$ \\
Fire suppression & $60(13.4)$ \\
Alarm response & $78(17.4)$ \\
Alarm return & $56(12.5)$ \\
Physical training & $42(9.4)$ \\
Emergency medical services and other nonfire emergencies & $69(15.4)$ \\
Fire-station and other nonemergency duties & \\
\hline * Data are based on narrative summaries from the records of the U.S. Fire Ad- \\
ministration, Federal Emergency Management Agency, for the period from \\
January 1, 1994, to December 31, 2004. ${ }^{19}$ \\
\hline
\end{tabular}

Table 2 shows the estimated proportion of time that firefighters spent each year in specific duties according to the three sources of firedepartment activity data that we used. Among firefighters in Cambridge (our municipal data set), approximately $2 \%$ of duty time was spent in fire suppression. Among firefighters in our large metropolitan data set, approximately $5 \%$ of duty time was spent in fire suppression. Finally, among all firefighters in the United States (as represented in our national data set), approximately $1 \%$ of duty time was spent in fire suppression.

Table 3 shows the frequency of observed deaths from coronary heart disease according to duty as compared with the expected frequency. The observed distribution of deaths was significantly different from the expected distribution based on the estimates from each of the three data sources $(\mathrm{P}<$ 0.001 for the three comparisons). The ratios of observed to expected deaths associated with the various duties of firefighters were consistently higher than 1 , with the exception of nonfire emergencies and nonemergency duties. Although 32\% of deaths occurred during fire suppression, this activity was estimated to account for as little as 1 to $5 \%$ of the average firefighter's professional time per year, so this duty was associated with the most significantly elevated ratios of observed to expected deaths.

\begin{tabular}{|c|c|c|c|}
\hline Variable & $\begin{array}{c}\text { Municipal Fire } \\
\text { Department }\end{array}$ & $\begin{array}{l}\text { Large Metropolitan Fire } \\
\text { Departments }\end{array}$ & National Data \\
\hline \multicolumn{4}{|l|}{ Fire service activity } \\
\hline Population served (no.) & 101,355 & $760,935 \pm 888,916$ & $280,000,000$ \\
\hline Uniformed firefighters (no.) & 274 & $1063 \pm 785$ & $1,082,855 \pm 14,446$ \\
\hline Population served per firefighter (no.) & 370 & $655 \pm 218$ & $259 \pm 3$ \\
\hline Emergency incidents (no./firefighter/yr) & 44 & $92 \pm 24$ & $18 \pm 2$ \\
\hline Fire incidents (no./firefighter/yr) & 2.0 & $7.0 \pm 6.3$ & $1.7 \pm 0.1$ \\
\hline \multicolumn{4}{|l|}{ Duties (\% of annual time) } \\
\hline Fire suppression & 2 & 5 & 1 \\
\hline Alarm response & 6 & 9 & 4 \\
\hline Alarm return & 10 & 15 & 7 \\
\hline Physical training & 8 & 8 & 8 \\
\hline Emergency medical services and other nonfire emergencies & 23 & 34 & 15 \\
\hline Fire-station and other nonemergency duties & 51 & 29 & 65 \\
\hline
\end{tabular}

* Plus-minus values are means \pm SD. Municipal data are from the Cambridge Fire Department, Cambridge, Massachusetts (2002). ${ }^{18}$ Data for large metropolitan fire departments are from surveys of 17 large metropolitan fire departments conducted by the International Association of Fire Fighters (2005) (Moore-Merrell L: personal communication). National data are from annual national surveys conducted by the National Fire Protection Association (1994 through 2003). ${ }^{20}$ 
Table 4 includes the odds ratios and $95 \%$ CIs for the risk of death from coronary heart disease among firefighters engaged in each emergency duty and physical training as compared with the reference category of nonemergency tasks. On the basis of the three estimates of the time that firefighters spent on particular duties, death from coronary heart disease was 12 to 136 times as likely to occur during fire suppression as during nonemergency duties. An increased risk was also consistently observed for other emergency duties, as compared with nonemergency duties; the risk was increased by a factor of 2.8 to 14.1 during alarm response, 2.2 to 10.5 during alarm return, and 2.9 to 6.6 during physical training.

Figure 1A shows the risk of death from coronary heart disease per 1 million firefighters per year (deaths per 1 million person-years) for each duty according to age group, and Figure $1 \mathrm{~B}$ shows the risk of death according to job status (volunteer or professional). As might be expected, the risk of coronary heart disease generally increased with age for each type of duty, whereas the results for job status were mixed.

\section{DISCUSSION}

In this study, we used data from a nationwide registry of deaths among firefighters over an 11-year period and estimates from three different sources of time spent in various firefighting duties to estimate the duty-specific risks of death from coronary heart disease among firefighters. As compared with nonemergency duties, certain emergency duties and physical training were associated with an increased risk of death from coronary heart disease among firefighters. These findings are consistent with those of our previous, smaller study ${ }^{18}$ and with an analysis of cardiac events that led to retirement from firefighting. ${ }^{22}$

Fire suppression, which represents only about 1 to $5 \%$ of firefighters' professional time each year, accounted for $32 \%$ of deaths from coronary heart disease and was associated with a risk of death from coronary heart disease that was approximately 10 to 100 times as high as the risk associated with nonemergency duties. We think that the most likely explanation for these findings is the increased cardiovascular demand of fire suppression..$^{8,11}$

The risk of coronary heart disease events during fire suppression may be increased because

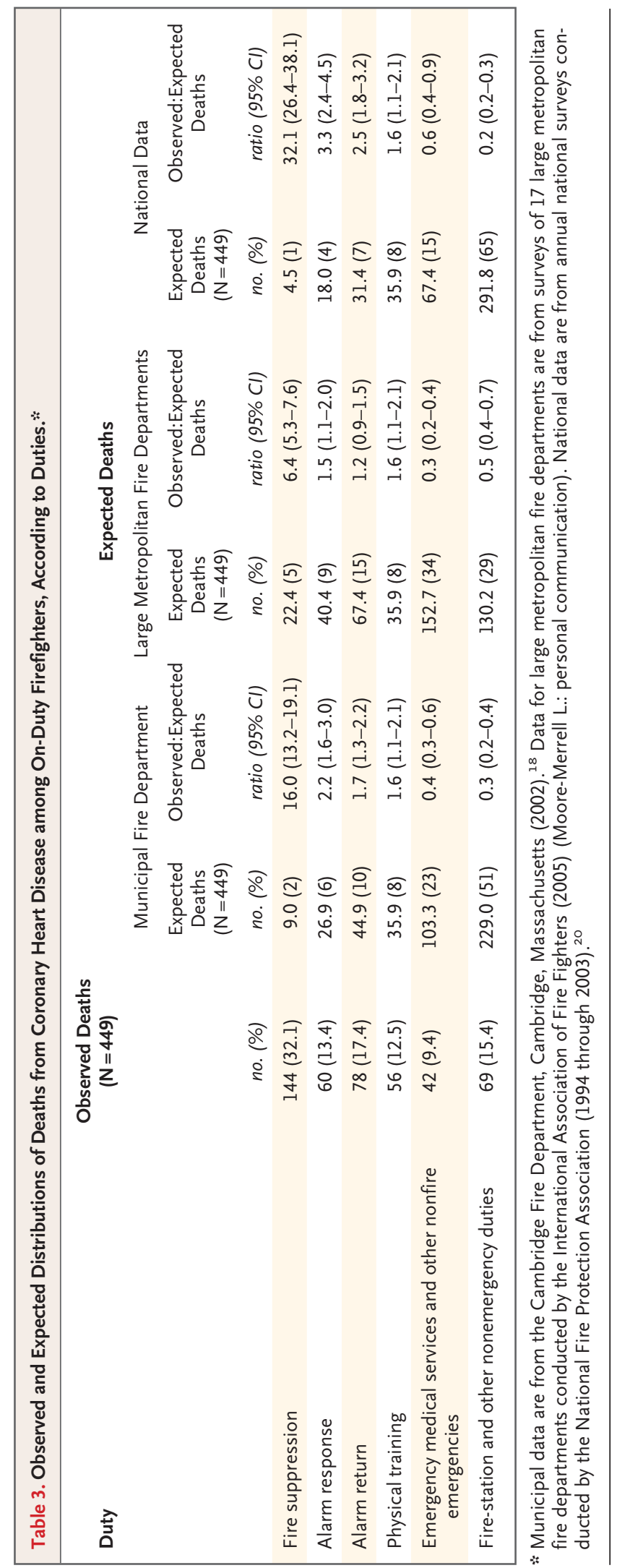




\begin{tabular}{|c|c|c|c|c|c|c|}
\hline \multirow[t]{2}{*}{ Duty } & \multicolumn{2}{|c|}{ Municipal Fire Department } & \multicolumn{2}{|c|}{$\begin{array}{c}\text { Large Metropolitan Fire } \\
\text { Departments }\end{array}$} & \multicolumn{2}{|c|}{ National Data } \\
\hline & $\begin{array}{l}\text { Odds Ratio } \\
(95 \% \mathrm{Cl})\end{array}$ & P Value & $\begin{array}{l}\text { Odds Ratio } \\
(95 \% \mathrm{Cl})\end{array}$ & P Value & $\begin{array}{l}\text { Odds Ratio } \\
(95 \% \mathrm{Cl})\end{array}$ & P Value \\
\hline Fire suppression & $53(40-72)$ & $<0.001$ & $12.1(9.0-16.4)$ & $<0.001$ & $136(101-183)$ & $<0.001$ \\
\hline Alarm response & $7.4(5.1-11)$ & $<0.001$ & $2.8(1.9-4.0)$ & $<0.001$ & $14.1(9.8-20.3)$ & $<0.001$ \\
\hline Alarm return & $5.8(4.1-8.1)$ & $<0.001$ & $2.2(1.6-3.1)$ & $<0.001$ & $10.5(7.5-14.7)$ & $<0.001$ \\
\hline $\begin{array}{l}\text { Emergency medical services and } \\
\text { other nonfire emergencies }\end{array}$ & $1.3(0.9-2.0)$ & 0.16 & $0.5(0.3-0.8)$ & $<0.001$ & $2.6(1.8-3.9)$ & $<0.001$ \\
\hline Physical training & $5.2(3.6-7.5)$ & $<0.001$ & $2.9(2.0-4.2)$ & $<0.001$ & $6.6(4.6-9.5)$ & $<0.001$ \\
\hline $\begin{array}{l}\text { Nonemergency duties (fire sta- } \\
\text { tion and other) }\end{array}$ & 1.0 & & 1.0 & & 1.0 & \\
\hline
\end{tabular}

* Municipal data are from the Cambridge Fire Department, Cambridge, Massachusetts (2002). ${ }^{18}$ Data for large metropolitan fire departments are from surveys of 17 large metropolitan fire departments conducted by the International Association of Fire Fighters (2005) (Moore-Merrell L.: personal communication). National data are from annual national surveys conducted by the National Fire Protection Association (1994 through 2003). ${ }^{20}$

many firefighters lack adequate physical fitness, have underlying cardiovascular risk factors, and have subclinical or clinical coronary heart disease. Even new firefighter recruits may be overweight and have low-to-normal aerobic capacities. ${ }^{23}$ Such problems are compounded during career tenure because more than $70 \%$ of fire departments lack programs to promote fitness and health. ${ }^{1}$ Most fire departments do not require firefighters to exercise regularly, undergo periodic medical examinations, or have mandatory return-to-work evaluations after a major illness. In addition, several studies have shown the high prevalence of risk factors for cardiovascular disease among firefighters ${ }^{24-29}$ as well as lower-than-expected exercise tolerance. ${ }^{30,31}$ Moreover, two studies have shown that among firefighters who had fatal events $^{18}$ or nonfatal events ${ }^{22}$ related to coronary heart disease while on duty, $26 \%$ and $18 \%$, respectively, had previously received a diagnosis of coronary heart disease, peripheral vascular disease, or cerebrovascular disease, and among the remainder, smoking, hypertension, and diabetes mellitus were significantly more prevalent than among active firefighters in the control group. Likewise, in our study, the risk of death from coronary heart disease increased with age for all types of duty. Unexpectedly, professional and volunteer firefighters had different risks of death from coronary heart disease, depending on the type of duty performed, although for both groups, the risk was highest during fire suppression.
In parallel with our finding of a significantly increased risk of death from coronary heart disease during fire suppression, as compared with nonemergency duties, the risk was significantly elevated during physical training. This finding is consistent with investigations implicating intense physical activity as a strong triggering factor, especially among physically inactive persons. ${ }^{32-35}$ Also consistent with the triggering hypothesis and with research documenting increased heart rates among firefighters responding to alarms $\mathrm{s}^{8,9}$ was our finding that the risk of death from coronary heart disease associated with alarm response and alarm return was approximately five to seven times as high as that associated with nonemergency duties. Emergency medical services and other nonfire emergency responses were not associated with a significant increase in risk. These findings are consistent with the much lower proportion of deaths from coronary heart disease among emergency medical services workers who are not firefighters ${ }^{3}$ than among firefighters, and may reflect a lower level of exposure to physically demanding emergencies.

One limitation of our study is that the estimates of odds ratios for specific job duties are based on fairly wide approximations of time spent on different duties. The average work year of a professional firefighter in a major urban center is probably much different from that of a rural volunteer firefighter. In addition, there have been few if any comprehensive studies of how fire- 
fighters spend their time. Our estimate of the increase in risk is therefore subject to considerable uncertainty. However, even in the most conservative scenario (with the use of the time estimates from the large metropolitan fire departments), the risks associated with fire suppression remained remarkably high and were also significantly increased for alarm response, alarm return, and physical training.

Also, our three sets of risk estimates are not based on three completely distinct calculations. In each case, one set of national figures for "observed" deaths was used, and the resulting odds ratios represent risk relative to nonemergency duties, not absolute risks for one group of firefighters as compared with another. Our results should therefore not be used to suggest that the risk of death from coronary heart disease during fire suppression is higher in a small community fire department than in a large metropolitan fire department. Instead, the three calculations provide a range of estimates of the average risk for firefighters nationwide. Because only $14 \%$ of firefighters in the United States serve populations larger than 100,000 residents, ${ }^{21}$ we think that the average risk for most firefighters probably falls between the risk based on estimates of time spent in particular duties that were derived from a single municipal fire department and the risk based on the nationwide time estimates. Our estimate that fire suppression accounts for 1 to $2 \%$ of annual work time (for the nationwide and municipal scenarios, respectively) is consistent with a study of a large fire department in Montreal, ${ }^{36}$ where fire suppression accounted for 0.7 to $2.5 \%$ of annual work time.

A second limitation of our study was the need to base our evaluation on brief narratives, which lacked autopsy information for some of the deaths. However, the misclassification of deaths due to inadequate information would have contributed to a random error, most likely diluting the results of our study toward the null hypothesis. Although 26 deaths from cardiovascular but not coronary heart disease were excluded, this small number was unlikely to bias the overall results in a specific direction.

A third limitation of our analysis was the starting assumption that the number of deaths from coronary heart disease that occur during any given firefighting duty should be directly proportional to the amount of time spent perform-

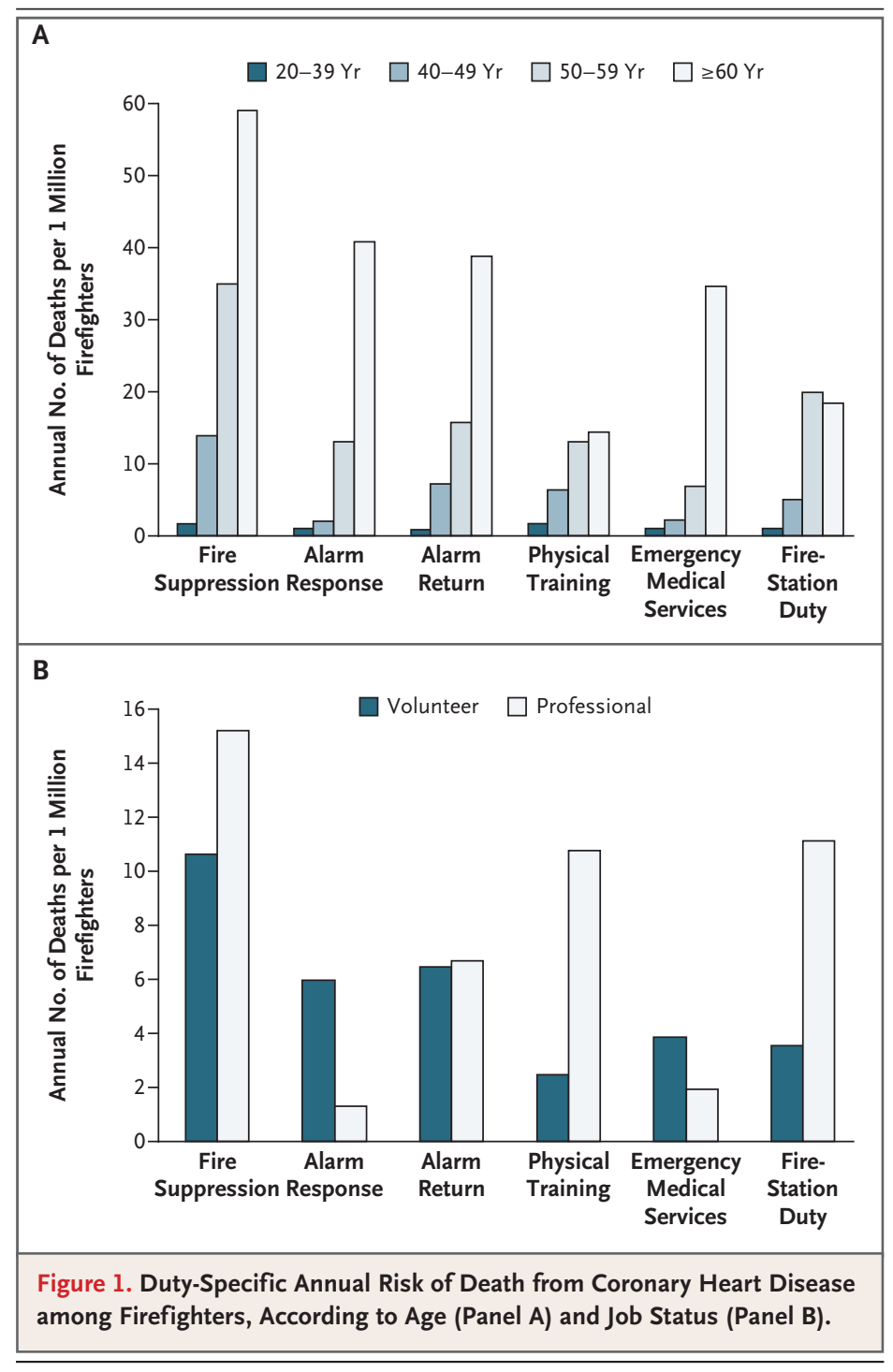

ing that duty. It is well established, for example, that the risk of coronary heart disease events varies according to the time of day, ${ }^{37}$ as well as the season of the year. ${ }^{38}$ In this study, we could not examine the circadian pattern of deaths. However, in our previous, smaller study ${ }^{18}$ and in another, 10-year analysis, ${ }^{2} 67$ to $77 \%$ of deaths from cardiac causes among on-duty firefighters occurred between noon and midnight, as did more than $60 \%$ of emergency responses. This pattern is in stark contrast to the peak period for cardiovascular events in the general population, which is 6 a.m. to noon. With respect to season, deaths from cardiac causes among firefighters are most frequent in the winter, as they are in the general population. When we analyzed duty-specific risks 
separately for each of the four seasons, however, the resulting point estimates for each duty remained similar in magnitude and close to the range of our original confidence intervals. Finally, although we cannot completely account for the effects of the time of day and season, the highest estimates of these effects on event rates are at least an order of magnitude smaller than the relative risks we observed for specific duties.

In conclusion, we analyzed nationwide data on deaths among firefighters, as well as three separate estimates of time spent in various firefighting duties, to determine the duty-specific risks of death from coronary heart disease among firefighters. Our analysis showed that specific duties, especially fire suppression but also alarm response, alarm return, and physical training, are associated with significant increases in risk.

Supported in part by grants from the National Institute for Occupational Safety and Health (T42/CCT122961-02, to Dr. Kales) and the Massachusetts Public Employees Retirement Administration Commission (to Dr. Kales). The funders had no involvement in the study design, data collection and analysis, writing of the paper, or decision to submit the paper for publication.

Dr. Kales and Dr. Christiani report serving as paid expert witnesses, independent medical examiners, or both in workers' compensation and disability cases, including cases involving firefighters. No other potential conflict of interest relevant to this article was reported.

We thank Ken Pitts, John Gelinas, and Lori Moore-Merrell for providing fire-department incident, response, activity, and survey data.
REFERENCES

1. Fahy RF. U.S. firefighter fatalities due to sudden cardiac death, 1995-2004. Quincy, MA: National Fire Protection As sociation, June 2005. (Accessed February 21, 2007, at http://www.nfpa.org/assets/ files/PDF/OSCardiacDeath.pdf.)

2. Firefighter fatality retrospective study, April 2002. (Prepared for the Federal Emergency Management Agency, United States Fire Service, National Fire Data Center. Arlington, VA: TriData Corp., 2002.

3. Maguire BJ, Hunting KL, Smith GS, Levick NR. Occupational fatalities in emergency medical services: a hidden crisis. Ann Emerg Med 2002;40:625-32.

4. Franke WD, Anderson DF. Relation ship between physical activity and risk factors for cardiovascular disease among law enforcement officers. J Occup Med 1994;36:1127-32.

5. Fisher NG, Nicol ED. Cardiological disease in the Armed Forces: a clear and present danger. J R Nav Med Serv 2005; 91:112-7.

6. Melius J. Occupational health for firefighters. Occup Med 2001;16:101-8.

7. Guidotti TL. Human factors in firefighting: ergonomic-, cardiopulmonaryand psychogenic stress-related issues. Int Arch Occup Environ Health 1992;64: 1-12.

8. Barnard RJ, Duncan HW. Heart rate and ECG responses of fire fighters. J Oc cup Med 1975;17:247-50.

9. Kuorinka I, Korhonen O. Firefighters' reaction to alarm, an ECG and heart rate study. J Occup Med 1981;23:762-6.

10. Burgess JL, Nanson CJ, Bolstad-Johnson DM, et al. Adverse respiratory effects following overhaul in firefighters. J Occup Environ Med 2001;43:467-73.

11. Smith DL, Manning TS, Petruzzello SJ Effect of strenuous live-fire drills on cardiovascular and psychological responses of recruit firefighters. Ergonomics 2001; 44:244-54.
12. Kawachi I, Colditz GA, Stampfer MJ, et al. Prospective study of shift work and risk of coronary heart disease in women. Circulation 1995;92:3178-82.

13. Friel JK, Stones M. Firefighters and heart disease. Am J Public Health 1992;82 1175-6.

14. International Association of Fire Fighters. Presumptive legislation. (Accessed Feb ruary 21 , 2007, at http://www.iaff.org/safe/ content/presumptive/infselect.asp.)

15. Steenland K. Epidemiology of occupation and coronary heart disease: research agenda. Am J Ind Med 1996;30:495-9. 16. Guidotti TL. Occupational mortality among firefighters: assessing the association. J Occup Environ Med 1995;37:1348-56 17. Haas NS, Gochfeld M, Robson MG Wartenberg D. Latent health effects in firefighters. Int J Occup Environ Health 2003;9:95-103.

18. Kales SN, Soteriades ES, Christoudias SG, Christiani DC. Firefighters and onduty deaths from coronary heart disease: a case control study. Environ Health 2003 2:14.

19. United States Fire Administration Firefighter fatalities. (Accessed February 21, 2007, at http://www.usfa.fema.gov/ fatalities/.)

20. National Fire Protection Association. Fire statistics, U.S. fire service. (Accessed February 21, 2007, at http://www.nfpa. org/categoryList.asp? categoryID $=955 \&$ URL=Research\%20\&\%20Reports/ Fire\%20statistics/Fire\%20service.) 21. Karter MJ. U.S. fire department profile through 2000. Quincy, MA: National Fire Protection Association, 2001. 22. Holder JD, Stallings LA, Peeples L, Burress JW, Kales SN. Firefighter heart presumption retirements in Massachusetts: 1997-2004. J Occup Environ Med 2006;48: 1047-53.

23. Roberts MA, O'Dea J, Boyce A, Mannix ET. Fitness levels of firefighter recruits before and after a supervised exercise training program. J Strength Cond Res 2002;16:271-7.

24. Kales SN, Polyhronopoulos GN, Aldrich JM, Leitao EO, Christiani DC. Correlates of body mass index in hazardous materials firefighters. J Occup Environ Med 1999;41:589-95.

25. Clark S, Rene A, Theurer WM, Marshall M. Association of body mass index and health status in firefighters. J Occup Environ Med 2002;44:940-6.

26. Soteriades ES, Hauser R, Kawachi I, Liarokapis D, Christiani DC, Kales SN. Obesity and cardiovascular disease risk factors in firefighters: a prospective cohort study. Obes Res 2005;13:1756-63.

27. Ide CW. A longitudinal survey of the evolution of some cardiovascular risk factors during the careers of male firefighters retiring from Strathclyde Fire Brigade from 1985-1994. Scott Med J 2000;45:7983.

28. Glueck CJ, Kelley W, Wang P, Gartside PS, Black D, Tracy T. Risk factors for coronary heart disease among firefighters in Cincinnati. Am J Ind Med 1996;30:33140.

29. Soteriades ES, Kales SN, Liarokapis D, Christoudias SG, Tucker SA, Christiani DC. Lipid profile of firefighters over time: opportunities for prevention. J Occup Environ Med 2002;44:840-6.

30. Lemon PW, Hermiston RT. Physiological profile of professional fire fighters. J Occup Med 1977;19:337-40.

31. Kales SN, Christiani DC. Cardiovascular fitness in firefighters. J Occup Environ Med 2000;42:467-8.

32. Johnstone MT, Mittleman M, Tofler $\mathrm{G}$, Muller JE. The pathophysiology of the onset of morning cardiovascular events. Am J Hypertens 1996;9:22S-28S.

33. Mittleman MA, Maclure M, Tofler GH, Sherwood JB, Goldberg RJ, Muller JE. Triggering of acute myocardial infarction 
by heavy physical exertion: protection against triggering by regular exertion. N Engl J Med 1993;329:1677-83.

34. Franklin BA, Bonzheim K, Gordon S, Timmis GC. Snow shoveling: a trigger for acute myocardial infarction and sudden coronary death. Am J Cardiol 1996;77: 855-8.

35. Willich SN, Klatt S, Arntz HR. Circadian variation and triggers of acute coro- nary syndromes. Eur Heart J 1998;19: Suppl C:C12-C23.

36. Austin CC, Dussault G, Ecobichon DJ.

Municipal firefighter exposure groups, time spent at fires and use of self-contained-breathing-apparatus. Am J Ind Med 2001;40:683-92.

37. Cohen MC, Rohtla KM, Lavery CE, Muller JE, Mittleman MA. Meta-analysis of the morning excess of acute myocardia infarction and sudden cardiac death. Am J Cardiol 1997;79:1512-6. [Erratum, Am J Cardiol 1998;81:260.]

38. Spencer FA, Goldberg RJ, Becker RC, Gore JM. Seasonal distribution of acute myocardial infarction in the second $\mathrm{Na}$ tional Registry of Myocardial Infarction. J Am Coll Cardiol 1998;31:1226-33.

Copyright @ 2007 Massachusetts Medical Society. 